\title{
Effects of Added Shelter and Stocking Density on Growth of Sleepy Cod Oxyeleotris lineolatus in Ponds
}

\author{
Brett W. Herbert and Peter A. Graham \\ Department of Primary Industries, Freshwater Fisheries and Aquaculture Centre, \\ Kennedy Highway, Walkamin, Queensland 4872 Australia \\ SCO'TT D. FOSTER \\ Biometry Unit, Department of Primary Industries, Centre for Tropical Agriculture, \\ PO Box 1054, Mareeba 4880 Australia
}

\begin{abstract}
Sleepy cod Oxyeleotris lineolatus is a species of freshwater goby in demand in Australian markets by consumers of Asian origin. It is related to marble goby Oxyeleotris marmoratus, the most expensive freshwater food fish in Asia, which is cultured throughout southeast Asia in ponds and cages. The performance of sleepy cod in culture conditions was investigated to assess the viability of farming them in northern Australia. Sleepy cod fingerlings (62.8 \pm 0.8 $\mathrm{mm}$ total length and $2.56 \pm 0.095 \mathrm{~g}$ ) were stocked into experimental ponds at 32,857 fish/ha, and grown out for 8 mo. Shelter was provided in each of three replicate ponds and was absent in three control ponds. The provision of shelter in juvenile growout was found to be of no benefit, although fish in ponds provided with shelter weighed slightly more per unit length than fish in ponds without shelter. Cannibalism was not a problem in growout, and survival was close to $100 \%$. After the shelter trial was completed, fish were graded into large and small classes (three replicates of each), and grown out without shelter at the same density for $158 \mathrm{~d}$. Following that, fish were again graded, and the largest $30 \%$ retained from growout at a density of $8,857 \mathrm{fish} / \mathrm{ha}$ (large, $198 \pm 6.44 \mathrm{~g}$ ) or 10,000 fish/ha (small, $48.9 \pm 1.27 \mathrm{~g}$ ). These were grown out for $188 \mathrm{~d}$. Growth of selected stock at low densities was slower than earlier growth rates, although smaller fish gained weight more rapidly than larger fish. Growth rates were better than the only published data for marble goby. Further investigation into high density culture and different genotypes of sleepy cod needs to be undertaken to determine the viability of pond culture.
\end{abstract}

The sleepy cod Oxyeleotris lineolatus is a gobiid fish distributed throughout northern Australia (Herbert and Peeters 1995). It is a highly regarded food fish, with firm, white flaky flesh (Lake 1978; Larson and Martin 1989). It is not prone to muddy flavors and taints common in some other farmed freshwater fish (Mosig 2002). Sleepy cod can grow up to $3.25 \mathrm{~kg}$ and 900 $\mathrm{mm}$ total length (TL) (Terry Vallance, Queensland Fisheries Service, Walkamin, personal communication 2001), but are common from 0.5 to $1 \mathrm{~kg}$ in their natural habitat (Herbert et al. 1995). Live sleepy cod have been sold for AU $\$ 28 / \mathrm{kg}$ wholesale in Sydney in 1999 (David Chan, Chinatown Fish market, Sydney, personal communication). Currently, production is lim- ited to experimental scale rearing in recirculating systems, as there is no commercial harvest of wild stocks (Mosig 2002). Export potential is also high, as there is an established market for the congener marble goby Oxyeleotris marmoratus in Malaysia and Thailand (FAO 1998). Thus, sleepy cod have high market value and demand, which warrants further investigation into their culture potential.

Pond culture of marble goby in Southeast Asia has not been well documented. Initial work in Singapore indicated that growth rates were highly variable in ponds stocked with hatchery-reared marble gobies, with growth from $0.57 \mathrm{~g}$ to $175 \mathrm{~g}$ over $16 \mathrm{mo}$, and survival was $44 \%$ (Tay and Seow 1974). For sleepy cod culture to be viable, 
a growth to market size in 18 mo would be necessary, at current market prices. The preferred market size in Australia is 400$600 \mathrm{~g}$ fish (David Chan, Chinatown Fish market, Sydney, personal communication). Information on growth rates of sleepy cod is essential to determine if aquaculture of this species will be economically viable.

Provision of shelter is an important means of increasing survival and growth of some species in aquaculture (Curran and Able 1998; Hossain et al. 1998; Jones et al. 1998). It has been reported that sleepy cod are territorial (MacKinnon and Herbert 1996) and cannibalistic if food is inadequate (Mosig 2002). Because of their territorial nature, the provision of shelter may be important for optimum survival, growth, and size frequency distributions of sleepy cod raised under intensive conditions.

The goal of this project was to determine the effect of shelter on survival and growth of sleepy cod in a nursery phase, and to determine the growth rate of sleepy cod in pond culture conditions.

\section{Materials and Methods}

\section{Stock Collection and Production, Experimental Ponds}

Broodstock sleepy cod were collected during the summer of 1997-1998 in the Walsh River, $100 \mathrm{~km}$ east of Cairns, Australia, by electrofishing. Fingerlings were produced using methods described in Mosig (2002). The six ponds used for the trials were $350 \mathrm{~m}^{2}(16 \mathrm{~m} \times 22 \mathrm{~m}, 1.4 \mathrm{~m}$ deep at outlet), polyethylene lined with a layer of soil $300 \mathrm{~mm}$ deep over the liner. Ponds were enclosed by nets and sheet metal fencing to exclude predators. Ponds were aerated using airlifts (Jones and Ruscoe 2001), and fish were fed a commercial sinking diet daily in the morning and afternoon $(43 \%$ protein, $15 \%$ lipid, $22 \%$ carbohydrate, $9 \%$ moisture, $11 \%$ ash, 17.2 MJ digestible energy per $\mathrm{kg}$ ) (Pivot sinking barramundi grower diet 43/15, Pivot Co., Rosny Park, Tasmania). Food was distributed evenly across each pond by hand. Feed rate was monitored by use of feeding trays and by observation for uneaten food several hours after feeding. All fish were fed slightly to excess. Food conversions were calculated by weight of food fed divided by the increase in biomass in a specific time period. Specific growth rate was calculated using the equation $(\ln \mathrm{Y} 2-\ln \mathrm{Y} 1) /(\mathrm{t} 2-\mathrm{t} 1)$ where $\ln$ is natural logarithm, $Y$ is weight of fish, $t$ is time in days, and 1 is the beginning of the experiment and 2 is the end (Busacker et al. 1990).

Temperature loggers recorded temperatures hourly throughout the course of the experiment. A calibrated TPS 90FL water checker meter (TPS Pty Ltd, Springwood, Australia) was used to measure oxygen, $\mathrm{pH}$, conductivity, and temperature. Pond water quality was checked at $1400 \mathrm{~h}$ on two afternoons a week, and additionally if ponds appeared green. Additionally, 24-h profiles, when the meter was programmed to record readings hourly, were also done to check morning dissolved oxygen levels. Mean, maximum, and minimum water quality parameters reported in results are from all six ponds over the relevant time period. Means exclude $24-\mathrm{h}$ profiles, maximums and minimums include results from them. If $\mathrm{pH}$ exceeded 9, the pond level was dropped by approximately $50 \%$ and refilled with fresh water. Ammonia levels were checked using a Hach DR70 spectrophotometer when food consumption was lower than expected, or when $\mathrm{pH}$ was over 8.5. Sick fish were examined for disease; this only occurred during the final phase of the trial.

A subsample of 50 fish was collected from each pond every $4 \mathrm{wk}$ to estimate growth. These fish were collected using a knotless 1- or 5-mm mesh seine net dragged through approximately half of the pond. In ponds provided with shelters, these were left in the net until it was dragged clear of the water. Shelters were then removed, shaken to dislodge fish in them, and then returned to the same location in the pond. To facilitate capture, the level of each pond 
was reduced to approximately $0.6-\mathrm{m}$ depth and refilled while the fish were being measured. This effected a water change of approximately $50 \%$ once every month. Fish were anesthetized using aqui-S (isoeuganol, $540 \mathrm{~g} / \mathrm{L}$ ) during measurement, and treated with 10-ppt salt bath for $1 \mathrm{~h}$ after handling.

The appropriate grading size, based on size frequencies and required number of animals, was calculated from the subsample measurements. Fish were then hand graded and counted while anesthetized, and then treated in a 10-ppt salt bath for $1 \mathrm{~h}$ after grading. Fish behavior was observed both during and after feeding, and when sampling.

\section{Shelter Trial}

Three-month-old graded fingerlings (average $62.8 \pm 0.8 \mathrm{~mm}$ long and $2.56 \pm$ $0.095 \mathrm{~g}$ weight) were stocked in six replicate ponds at 1,150 fish per pond $(32,857$ fish/ha). Three ponds were provided with 32 pipe stack shelters each (Jones and Ruscoe 2001), distributed evenly across the pond bottom. The three control ponds had no shelter. Ponds were stocked on 12 March 1999 and harvested on 1 November 1999. At the end of the trial, all fish from each pond were harvested by draining, and then weighed. A subsample of 50 from each pond was also measured (for length).

To assess the growth rates over time, REML (Restricted Maximum Likelihood) repeated measures analysis (Verbyla et al. 1999) was used. The models were computed in the Splus statistical package using the function samm (Butler et al. 2001). Size frequency distribution at harvest of the two treatments was compared using the Kolmorogov-Smirnov 2-sample test. Plots of the empirical cumulative distribution functions for both end weight and end total length were produced. Additionally, difference in body proportion was tested by comparing the length-weight relationship between treatments. A smoothing spline (estimated by REML) was fitted to both the habitat and control treatments. These splines were then tested for differences between treatments and for linearity (Verbyla et al. 1999). All the data from the shelter trial were used in the analysis.

On several occasions shelters were collected inside a dip net to determine if fish were actually using them. A dip net was slipped under the shelter and lifted so that the entire shelter was in the bag of the net, so that sleepy cod within the net could not escape. Use of shelters was also observed during monthly samplings.

\section{Growout of Graded Fish}

The growout trial was conducted in two phases. Phase one started on 4 November 1999. Each fish from the shelter trial was weighed, graded into two size classes: large (mean $135.44 \pm 2.26 \mathrm{~mm} ; 31.16 \pm 2.04 \mathrm{~g}$ ) and small (110.87 $\pm 0.53 \mathrm{~mm} ; 15.03 \pm$ $0.24 \mathrm{~g})$ and 1,100 were stocked into each of six ponds $(31,428 \mathrm{fish} / \mathrm{ha})$ without shelter. A sample of 50 fish was collected every 4 wk using a knotless 5-mm mesh seine net, and measured and weighed. Handling procedures are detailed above. On 12 April 2000 each pond was harvested, every fish weighed, and a subsample of 50 fish from each pond measured. Fish were then held in tanks for phase two.

Phase two started in 14 April 2000. The fish harvested on 12 April were graded and the largest 1,953 fish selected for further growout. Two subsamples of 75 of each of two grades of these was measured as a start point for this phase of the trial. The larger number of fish measured accounted for the greater variation in the size of fish being restocked. Three ponds were stocked with 301 'large' (mean $197.13 \pm 1.92 \mathrm{~mm}$; $198.10 \pm 6.44 \mathrm{~g} ; 8,857 \mathrm{fish} / \mathrm{ha}$ ) fish each, and three with 350 'small' fish (133.53 $6.64 \mathrm{~mm} ; 48.88 \pm 1.27 \mathrm{~g} ; 10,000 \mathrm{fish} / \mathrm{ha}$ ). Feed rate during both phases adjusted to actual feeding rate, based on use of $1-\mathrm{m} \mathrm{di}$ ameter feeding trays and observation of uneaten pellets. Ponds with large fish were harvested on 20 October 2000, and ponds with small fish trials were harvested on 13 
TABLE 1. Comparison of sleepy cod growth and survival after 8 mo in shelter and no shelter treatments.

\begin{tabular}{lcccccc}
\hline \multicolumn{1}{c}{ Treatment } & \multicolumn{3}{c}{ Shelter } & \multicolumn{4}{c}{ No shelter } \\
\hline Replicate & 1 & 2 & 3 & 1 & 2 & 3 \\
Average final weight & 22.7 & 21.7 & 21.6 & 20.2 & 24.0 & 21.1 \\
$\quad( \pm$ SE) & $( \pm 0.366)$ & $( \pm 0.328)$ & $( \pm 0.334)$ & $( \pm 0.286)$ & $( \pm 0.32)$ & $( \pm 0.271)$ \\
SGR $(\%)$ & 0.51 & 0.49 & 0.50 & 0.52 & 0.50 & 0.50 \\
Minimum & 4.9 & 8.3 & 4.3 & 5.7 & 5.5 & 6.5 \\
Maximum & 82.0 & 77.9 & 69.9 & 88.5 & 75.0 & 80.7 \\
Survival $(\%)$ & 98 & 96.9 & 97.1 & 97.6 & 97.6 & 98.3 \\
\hline
\end{tabular}

November 2000. As the initial sizes of the two groups (large and small) fish differed, weight, standard length, and total length were analyzed in conjunction with a derived variable, gain:

gain $=\frac{\text { final weight }- \text { initial weight }}{\text { initial weight }} \times 100$.

The analysis done was REML repeated measures analysis, as the observations on a pond are not independent, the correlation structures need to be accounted for.

\section{Results}

\section{Shelter Trial}

Survival in the ponds with shelter averaged $97 \%$ and nonshelter 99\%. Average weight of fish in ponds was $22.0 \pm 0.19 \mathrm{~g}$ $(N=3,504)$ in the sheltered treatments and $21.8 \pm 0.17 \mathrm{~g}(N=3,425)$ for unsheltered treatments (Table 1). Food conversion averaged $3.39 \pm 0.13$ for the shelter treatment and $3.39 \pm 0.04$ for no shelter. This estimate is high as feeding was always to excess.

During feeding, fish in the no shelter treatment rose in the water column and actively pursued and ate pellets as they sank. Fewer fish in the shelter treatment rose and ate pellets during observation, and those that did, did not emerge from shelters but were sitting on the bottom substrate in the open. Up to ten fish could be present in any one shelter at one time.

REML repeated measures analysis indicated no significant interaction for shelter and time - the fish increased in weight at the same rate irrespective of treatment. It did, however, suggest that the curves of total length over time are parallel but are significantly displaced from each other $(P=$ 0.048). The displacement of the shelter habitat was 1.411 less than the no shelter habitat, indicating that the fish were shorter in the shelter treatment.

The testing of the distributions of both fish weight and total length at the end of the shelter trial indicated differences between the shelter and no shelter treatments ( $P<0.001$ for weight and $P=0.004$ for length), further indicating that fish in ponds with shelter provided were heavier per unit of length.

Measured water quality variables were within acceptable ranges, and are presented in Table 2. Ammonia levels never exceeded $0.4 \mathrm{mg} / \mathrm{L}$.

\section{Growout of Graded Fish}

Phase 1. Initial growth was slow, but increased during the last 3 mo (February to April). At the end of phase one the large fish averaged $193.1 \pm 5.82 \mathrm{~mm}$ and 112.35 $\pm 10.12 \mathrm{~g}$, and the small fish $147.7 \pm 2.94$ $\mathrm{mm}$ and $42.36 \pm 4.75 \mathrm{~g}$. Water quality parameters are presented in Table 2 . The larger fish gained at a significantly higher rate than smaller fish relative to their initial size $(P=0.032)$. The relationship between gain and time was linear. Plots of standard length, total length, and weight all agreed with the gain data, in that the slopes of these variables over time was greater for the large fish than the small fish. Growth, gain, and survival data are presented in Table 3. 
TABLE 2. Water quality parameters during growout trials of sleepy cod.

\begin{tabular}{lcccccccc}
\hline & \multicolumn{2}{c}{ Shelter trial } & & \multicolumn{2}{c}{ Growout Phase 1 } & & \multicolumn{2}{c}{ Growout Phase 2 } \\
\cline { 2 - 3 } & Mean & Range & & Mean & Range & & Mean & Range \\
\hline Temperature & 22.1 & $16.6-28.6$ & & 26.8 & $23.1-30.2$ & & 21.2 & $16.3-27.0$ \\
Dissolved oxygen & 7.2 & $5.34-8.44$ & & 6.39 & $5.63-12.6$ & & 8.3 & $5.74-11.68$ \\
pH & 7.37 & $7.0-8.2$ & & 7.32 & $6.63-9.43$ & & 7.61 & $6.67-9.41$ \\
\hline
\end{tabular}

Phase 2. At the end of phase two large fish averaged $253.03 \pm 1.52 \mathrm{~mm}$ and $204.34 \pm 3.84 \mathrm{~g}$, and small fish $184.76 \pm$ $0.47 \mathrm{~mm}$ and $67.94 \pm 1.44 \mathrm{~g}$. Growth was minimal in the large group during the entire period after fish were split and the density reduced (Table 4). There was a significant difference in the slopes of the lines of gain for the different classes. There was no difference in condition of fish between or within treatments. Water quality parameters are presented in Table 2. This period included the winter months and spring (June to November). Growth across winter was similar to that in early spring. Temperature increases in spring had little impact on growth in the second, low-density phase. The size of fish appeared to affect the growth variables, particularly in the first, higher density, part of the growout trial. In the second phase of the growout trial, gain and growth were more static.

\section{Discussion}

\section{Shelter Trial}

The effects of shelter provision on growth and survival of fish in aquaculture ponds has been poorly studied. Phelps and de Gomez (1992) found that provision of shelter had a negative effect on net yield, survival, and feed conversion of channel catfish. Much of this effect was due to poorer survival in ponds with shelter, possibly due to increased predation. Predators were excluded in the current experiment and survival between treatments was not significantly different $(P=0.01)$, indicating that in a nursery phase, provision of shelter is not necessary. Sleepy cod provided with shelter were shorter than those without access to shelter. This may be attributed in part to the behavior of sleepy cod. When provided with shelter, sleepy cod lived in the shelters (up to ten fish per shelter) and many did not leave the shelter to eat. It is hypothesized that a significant proportion of fish living in shelters did not feed as often as those fish without shelter. The artificial diets fed were moderately high in fat $(15 \%$ fat), and fish eating these diets could be expected to be heavier than fish living on natural production. Sleepy cod from wild populations are significantly lighter than cultured fish of the same length (Mosig 2002). Fish in shelters would likely be less active than fish without shelter, and may have been fatter as a result of this.

TABLE 3. Growth, gain, and survival data for phase one of growout trials of sleepy cod after 119 d of growth.

\begin{tabular}{lcccccc}
\hline \multicolumn{1}{c}{ Treatment } & \multicolumn{3}{c}{ Large } & \multicolumn{3}{c}{ Small } \\
\hline Replicate & 1 & 2 & 3 & 4 & 5 & 6 \\
Average weight & 119.67 & 125.04 & 92.34 & 49.32 & 33.27 & 44.50 \\
$\quad( \pm S E)$ & $( \pm 12.97)$ & $( \pm 12.05)$ & $( \pm 10.44)$ & $( \pm 7.44)$ & $( \pm 2.80)$ & $( \pm 6.14)$ \\
Average gain (\%) & 284.03 & 301.27 & 196.34 & 228.12 & 121.34 & 196.06 \\
$( \pm S E)$ & $( \pm 41.60)$ & $( \pm 38.68)$ & $( \pm 33.52)$ & $( \pm 49.49)$ & $( \pm 18.60)$ & $( \pm 40.86)$ \\
SGR (\%) & 0.83 & 0.92 & 0.75 & 0.79 & 0.46 & 0.66 \\
Minimum weight & 30.94 & 29.86 & 29.82 & 22.6 & 18.83 & 24.95 \\
Maximum weight & 331.91 & 326.87 & 258.4 & 293.36 & 127.64 & 277.672 \\
Survival (\%) & 100 & 98.4 & 98.7 & 82.0 & 93.0 & 97.1 \\
\hline
\end{tabular}


TABLE 4. Growth, gain, and survival data for phase two of sleepy cod grow out trials, after 155 d of growth.

\begin{tabular}{lcccccc}
\hline \multicolumn{1}{c}{ Treatment } & \multicolumn{3}{c}{ Large } & \multicolumn{3}{c}{ Small } \\
\hline Replicate & 1 & 2 & 3 & 4 & 5 & 6 \\
Average weight & 211.54 & 198.44 & 203.04 & 66.35 & 66.66 & 70.81 \\
( \pm SE) & $( \pm 9.32)$ & $( \pm 9.24)$ & $( \pm 8.00)$ & $( \pm 1.87)$ & $( \pm 1.65)$ & $( \pm 1.98)$ \\
Average gain $(\%)$ & 6.78 & 0.17 & 2.49 & 35.73 & 36.38 & 44.88 \\
SGR (\%) & 0.035 & 0.001 & 0.013 & 0.143 & 0.146 & 0.174 \\
Minimum weight & 78.4 & 72.0 & 90.0 & 45.4 & 50.13 & 41.8 \\
Maximum weight & 424.0 & 410.0 & 317.0 & 103.5 & 113.0 & 105.8 \\
Survival (\%) & 100 & 98.4 & 98.7 & 82.0 & 93.0 & 97.1 \\
\hline
\end{tabular}

Cannibalism in many species of fish appears to be influenced by availability of shelter and food (Hecht and Applebaum 1988; Smith and Reay 1991; Jones et al. 1998). Sleepy cod in tanks are cannibalistic if not fed adequately, and cannibalism was observed in ponds where large numbers of fingerlings were inadequately fed (Mosig 2002). Cannibalism was also identified as the probable cause of low survival (44.2\%) in pond reared marble goby (Tay and Seow 1974). However, with provision of adequate food, cannibalism in sleepy cod ceases. The similar survival rates between treatments in this study indicate that for sleepy cod, provision of adequate food is more important to eliminate cannibalism than availability of refuges.

In sleepy cod, total length was found to be highly variable in relation to weight, whereas standard length was not. Future aquaculture studies on gobiid fishes should consider using standard length as a better indication of fish size than total length. The fish used in the shelter trial were all immature, so sexual dimorphism in fin morphology common in other gobiid fishes (Lake 1971) should not have accounted for this variability.

\section{Growout of Graded Fish}

The growth rate of sleepy cod at high densities is far slower than that of other carnivorous tropical fish, such as barramundi Lates calcarifer (MacKinnon et al. 1987; Parazo et al. 1998) or warmwater fish such as golden perch Macquaria ambigua (Mer- rick and Schmida 1984). In this study, only the fastest growing individuals (2\%) reached the minimum market size of $400 \mathrm{~g}$ in 19 mo. Only $13 \%$ of the fish in the original shelter study were retained in the large group of the second phase of the growout trial, which averaged $200 \mathrm{~g}$ after 19 mo. The only published study of marble goby growth (Tay and Seow 1974) found growth to $175.1(63-287.5) \mathrm{g}$ in $16 \mathrm{mo}$, when fed natural production (guppies and tilapia) and trash fish. At present, culture of marble goby is based on stocking wild caught juveniles $(15-100 \mathrm{~g})$. Culture of hatchery produced fingerlings has not been widely used because of the long growout period, indicated by the initial study in Singapore.

The pattern of growth suggests that a plateau in growth in sleepy cod is reached at around 14 mo age, in both small and large fish. Fish growth may reach a plateau for a variety of reasons, including dietary requirements (Jeong et al. 1992), temperature (Keast and Eadie 1984), and density (Baker and Ayles 1990). The plateau reached by sleepy cod may be age dependent, as both size classes stopped growing at about the same time. However, density may have been an overriding factor. For example, Murray cod Maccullochella peeli grow faster at high densities in recirculating systems (Ingram 2000). Sleepy cod grew faster during the high density phases of the trial, and behavioral changes may have been responsible for reduced growth at lower densities in ponds. No aggressive interactions were observed between feeding fish in the high- 
density phases, but interactions were seen during the low density phase. There may have been inhibition of feeding due to these interactions at lower densities.

The results of this trial suggest that sleepy cod culture in ponds may only be viable at high densities. Culture of sleepy cod in intensive systems will need to be investigated further to determine if growth rates can be maintained at high densities, where temperatures and water quality can be maintained at optimal levels. A temperature of above $22 \mathrm{C}$ is necessary to minimize disease problems and maximize growth rates (Mosig 2002). Trials in recirculating systems (using Fitzroy River strain sleepy cod) have indicated better growth rates than those achieved in this study (Mosig 2002), but this requires quantification before it is attempted on a large scale. Scientifically designed assessment of the different strains of sleepy cod is also essential to determine which strain is more suitable for intensive culture.

\section{Acknowledgments}

This work was fully funded by the Queensland Department of Primary Industries. Thanks to Ian Hockings, Clarita Agcopra, and Ben Hockings for assisting in management of fish and ponds, and to $\mathrm{He}$ len Larson and Clive Jones for reviewing the manuscript. Thanks also to Dave Bull and Bevan O'Grady for maintenance of equipment and assistance with harvests and data collection.

\section{Literature Cited}

Baker, R. F. and G. B. Ayles. 1990. The effects of varying density and loading level on the growth of Arctic charr (Salvelinus alpinus L.) and rainbow trout (Oncorhynchus mykiss). World Aquaculture 21:58-62.

Busacker, G. P., I. R. Adelman, and E. M. Goolish. 1990. Growth. Pages 363-387 in C. B. Schreck and P. B. Moyle, editors. Methods for fish biology. American Fisheries Society, Bethesda, Maryland, USA.

Butler, D. G., B. R. Cullis, A. R. Gilmoure, and B. J. Gogel. 2001. Samm reference manual. Biomet- ric Bulletin, Queensland Department of Primary Industries, Brisbane, Australia.

Curran, M. C. and K. W. Able. 1998. The value of tethering fishes (winter flounder and tautog) as a tool for assessing predation rates. Marine Ecology Progress Series 163:45-51.

FAO (Food and Agriculture Organization of the United Nations). 1998. Aquaculture production statistics 1987-1996. FAO, Rome, Italy.

Hecht, T. and S. Applebaum. 1988. Observation of intraspecific aggression and coeval sibling cannibalism by larval and juvenile Clarias gariepinus (Claridae: Pisces) under controlled conditions. Iournal of the Zoological Society (London) 214: $21-44$

Herbert, B. and J. Peeters. 1995. Freshwater fishes of Far North Queensland. Department of Primary Industries, Brisbane, Australia.

Herbert, B., J. Peeters, P. Graham, and A. E. Hogan. 1995. Natural Resources Analysis Program (NRAP) fish fauna survey project. Final report. Department of Primary Industries, Brisbane, Queensland, Australia.

Hossain, M. A. R., M. C. M. Beveridge, and G. S. Haylor. 1998. The effects of density, light and shelter on the growth and survival of African catfish (Clarias gariepinus Burchell, 1822) fingerlings. Aquaculture 160:25 1-258.

Ingram, B. A., editor. 2000. Murray Cod aquaculture: A potential for the new millennium. Proceedings of a workshop held 18th January 2000, Eildon, Victoria. Marine and Freshwater Resources Institute, Alexandra, Victoria, Australia.

Jeong, K-S, T. Takeuchi, N. Okamoto, and T. Watanabe. 1992. The effect of dietary gelatinized ratios at different energy levels on growth and chatacteristics of blood in rainbow trout fingerlings. Bulletin of the Japanese Society for Scientific Fisheries 58:937-944 (in Japanese).

Jones, C. L. W., H. Kaiser, and T. Hecht. 1998. Effect of shelter, broodstock number, and sex-ratio on juvenile production in the swordtail Xiphophorus helleri under intensive culture conditions. Journal of the World Aquaculture Society 29:9296.

Jones C. M. and I. M. Ruscoe. 2001. Assessment of five shelter types in the production of redclaw crayfish Cherax quadricarinatus (Decapoda: Parastacidae) under earthen pond conditions. Journal of the World Aquaculture Society 32:41-52.

Keast, A. and J. Eadie. 1984. Growth in the first summer of life: a comparison of nine co-occuring fish species. Canadian Journal of Zoology 62:12421250 .

Lake, J. S. 1971. Freshwater fishes \& rivers of Australia. Thomas Nelson, Melbourne, Australia.

Lake, J. S. 1978. Freshwater fishes of Australia. An 
illustrated field guide. Nelson, Melbourne, Australia.

Larson, H. K. and K. C. Martin. 1989. Freshwater fishes of the Northern Territory. Northern Territory Museum of Arts and Sciences handbook series number 1. Northern Territory Government Printing Office, Darwin, Northern Territory, Australia.

MacKinnon, M. and B. Herbert. 1996. Temperature, dissolved oxygen and stratification in a tropical reservoir, Lake Tinaroo, North Queensland, Australia. Marine and Freshwater Research 47(7): 937-949.

MacKinnon, M. R., S. Poole, E. Cazzola, and D. Bull. 1987. Pellet fed barramundi show potential for commercial farming. Australian Fisheries July: 42-44.

Merrick, L, R. and G. E. Schmida. 1984. Australian freshwater fishes. Griffin Press, Netley, Australia.

Mosig, J. 2002. Research on sleepy cod in North Queensland. Hatchery International 3(2):4-8.

Parazo, M. M., L. M. Garcia, F. G. Ayson, A. C.
Fermin, J. M. E. Almendras, D. M. Reyes, E. M. Avila, and J. D. Toledo. 1998. Sea bass hatchery operations. Aquaculture Extension Manual No. 18, Second edition. Southeast Asian Fishcries Development Center, Iloilo, Philippines.

Phelps, R. P. and A. S. de Gomez. 1992. Influence of shelter and feeding practices on channel catfish fingerling production. The Progressive Fish-Culturist 54:21-24.

Smith, C. and P. Reay. 1991. Cannibalism in teleost fishes. Reviews of Fish Biology and Fisheries Science 1:41-64.

Tay, S. H. and P. C. Seow. 1974. Observations on the monoculture of induced bred Oxyeleotris marmorata, Bleeker (Marble goby) in a pond at Sembawang. Singapore Journal of Primary Industries 2:150-154.

Verbyla, A. P., B. R. Cullis, M. G. Kenward, and S. J. Welham. 1999. The analysis of designed experiments and longitudinal data by using smoothing splines (with discussion). Applied Statistics 48:269-311. 